\title{
Experimental Thermoelectric Generation in a Porous Media Burner
}

\author{
Valeri I. Bubnovich, Nina Orlovskaya, Luis A. Henríquez-Vargas, and Francisco E. Ibacache
}

\begin{abstract}
An experimental study on combustion in porous media and thermoelectric generation was performed. The reactor was composed of two types of porous media where flame stabilization was reached at the interface of them. An external thermoelectric module was placed to harvest the thermal energy produced in the system. Maximum values of voltage and current obtained were $503 \mathrm{mV}$ and $150 \mathrm{~mA}$ respectively.
\end{abstract}

Index Terms-Energy conversion, super adiabatic combustion, thermoelectricity.

\section{INTRODUCTION}

Filtration combustion (FC) is generated when an incoming fuel/oxidizer mixture flows and reacts in the interstitial space of a porous matrix. Due to its better thermal properties, the porous material allows efficient redistribution of the energy released in the gas-phase chemical reaction [1]. In particular, energy feed-back from the hot products of combustion to the upstream region preheats the reagents and generates temperatures above the normal adiabatic limits for free flames. The excess of enthalpy generated allows sustained combustion for extremely low-calorie mixtures [2]-[4].

In the low-velocity regime of FC, classification given by [5] thermal and reaction waves propagates through the porous matrix at velocities of order $10^{-4} \mathrm{~m} / \mathrm{s}$. Propagation of reaction wave may occur either downstream or upstream, as pointed by analytical relations [2], [3], [5]-[8], numerical simulations [9], [10] and demonstrated with experimental results [11]-[13]. Upstream wave propagation leads to temperatures under the normal adiabatic conditions, producing the so-called subadiabatic effect. Stationary waves (immovable relative to the porous medium), exhibit equilibrium temperatures equal to normal laminar flames. Downstream wave propagation produces equilibrium temperatures above the normal adiabatic ones, giving the superadiabatic effect. Combustion front displacement direction depends mainly on fuel equivalence ratio, combustion enthalpy and heat exchange between solid and gas phase. As a result, if heat generation on the front exceeds heat absorption by porous media internal surface, the combustion front displaces

Manuscript received May 31, 2013; revised July 28, 2013. This work was supported by the by Conicyt-Chile under Fondecyt Grant 1131156 and 11100401

V. I. Bubnovich, L. A. Henríquez-Vargas, and F. E. Ibacache are with the Department of Chemical Engineering, University of Santiago of Chile, B. O’Higgins 3363, Santiago, Chile (e-mail: valeri.bubnovich@usach.cl, luis.henriquez@usach.cl, fibacaches@gmail.com).

N. Orlovskaya is with the Department of Mechanical, Materials and Aerospace Engineering, University of Central Florida, Orlando, FL, USA (email: norlovsk@mail.ucf.edu ). against gas filtration. On the contrary, dealing with lean mixture or combustibles with low calorific power, the combustion front displaces downstream.

Due to the unsteady nature of the FC phenomenon, confinement methods for the combustion front are necessary. From the alluded methods, it can be mentioned the reciprocal flow burner [14], [15], and stabilization based on the modified Peclet number for reactors with two sections of porous materials with different properties [7], [12], [16].

The use of thermoelectric elements to produce electricity as a direct conversion system from thermal energy provides several advantages: environmental friendliness, silent operation, no mechanical moving parts, no operating fluid employed, long life performance period [17]-[19]. However, the main drawback of the use of thermoelectric elements is its low conversion efficiency [20].

Thermoelectric generators operate by utilizing the Seebeck effect: a temperature difference across two jointed, but different, conducting materials will create a voltage. In order to further increase the voltage and power output, the temperature difference may be increased by increasing the hot-side temperature or decreasing the cool-side temperature across the device. Therefore, for a burner utilizing thermoelectric devices, the power generated can be maximized by increasing the combustion temperature, or by cooling the cool-side of the device through either passive means, like a heat-sink, or active means, like a fan or impinging air jet. It is standard to connect multiple thermoelectric devices together in series to increase the voltage and power outputs.

Coupling of an efficient combustion system and a thermoelectric generator is an attractive alternative to bring power to areas where, due to its nature, no electrical connection to a power grid can be realized. Among the systems devised can be cited: the combustion-thermoelectric tube [21], the catalytic micro-combustor with integrated thermoelectric elements [22], the reciprocal flow thermoelectric porous burner. The latter has been studied both numerically [23], [24] and experimentally [25].

The present work focuses on thermoelectric generation using a porous media burner with flame stabilization at the interface of two porous bodies.

\section{SYSTEM DESCRIPTION}

The prototype reactor is composed of a rectangular steel casing (A36) to house there the porous sections with dimensions, $7 \times 7 \mathrm{~cm}^{2}$ outer square section, $25.4 \mathrm{~cm}$ length, $5.08 \mathrm{~cm}$ internal diameter, see Fig. 1 .

Two highly porous pure alumina $\left(99.5 \mathrm{wt} \% \mathrm{Al}_{2} \mathrm{O}_{3}\right.$ ) 
reticulated foams $(76.2 \mathrm{~mm}$ long and $50.8 \mathrm{~mm}$ in diameter, porosity of $80 \%, 20$ ppi, Fig. 2D) placed at the downstream section of the reactor (Manufacturer: Süd-Chemie Hi-Tech Ceramics, Louisville, KY). A lower-porosity alumina honeycomb porous media (400 cells per square inch, Fig. 2A) placed at the upstream section to keep the flame confined (Manufacturer: Applied Ceramics, Laurens, SC).

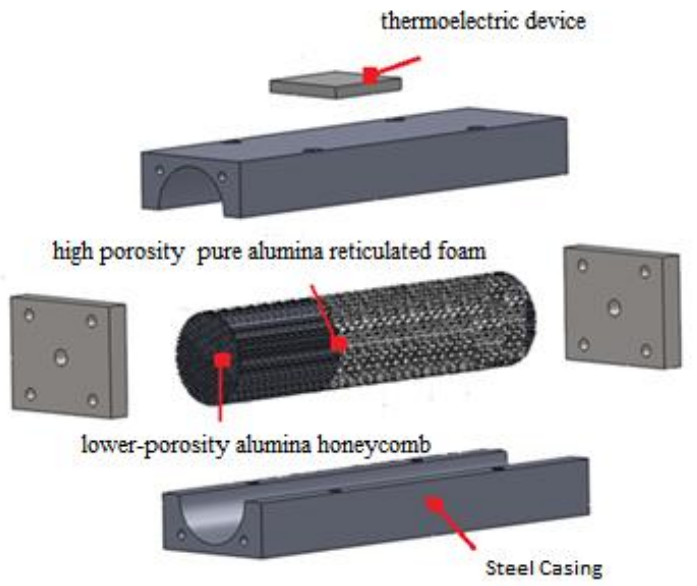

Fig. 1. Schematic of porous burner assembly
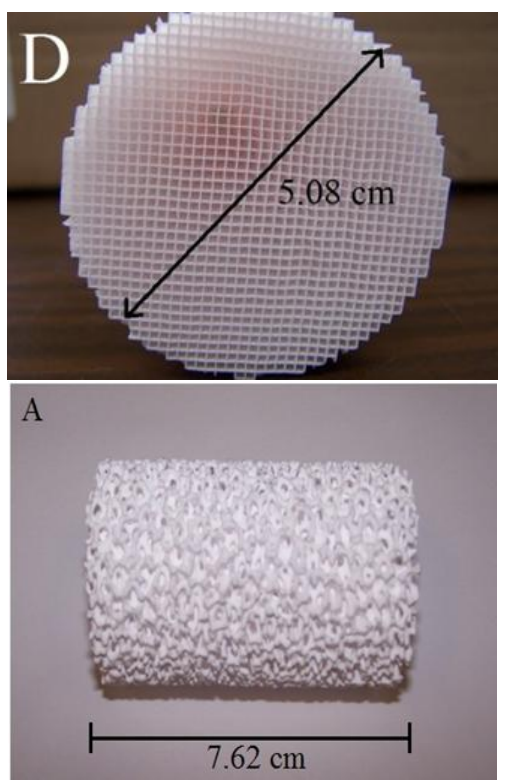

Fig. 2. Alumina reticulated (D) and honeycomb (A) porous foams

A thermoelectric module (TEM, Fig. 3) to harvest the heat released by combustion. The current work uses a commercially available $\mathrm{Bi}_{2} \mathrm{Te}_{3}$ alloy module. It has a maximum no-load power output of $7.5 \mathrm{~W}$, electrical resistance $0.9 \Omega$, hot side temperature limit of $300{ }^{\circ} \mathrm{C}$, cold side $180{ }^{\circ} \mathrm{C}$. (Model number 1261G-7L31-05CQ, Custom Thermoelectric). As additional insulation, a quartz piece was placed between the TEM and the reactor surface. An external electrical resistance to generate the matching condition in the system for maximum conversion efficiency.

Two hot wire anemometer flow controllers to measure the incoming air and fuel flows, capacity $250 \mathrm{l} / \mathrm{min}$ and $50 \mathrm{l} / \mathrm{min}$ respectively (Models FMA-2611A, FMA-2609A Manufacturer: OMEGA Engineering Inc., Standford, CT).

Three C-type (Fig. 4) and two K-type thermocouples that registered temperatures inside the reactor and in the interface reactor surface-TEM, respectively.

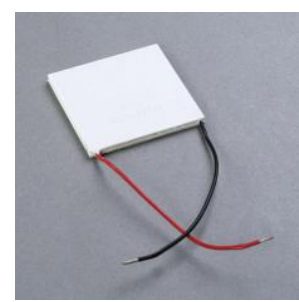

Fig. 3. Thermoelectric module 1261G-7L31-05CQ of the custom thermoelectric company

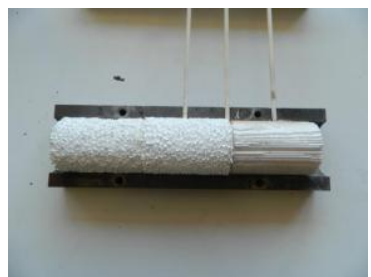

Fig. 4. Porous media and thermocouples disposition in the burner.

A Data acquisition system model OMB DAQ 56, USB interface, 10 channels for register system temperatures. An air compressor Schulz, model MSV6/30 to propel air. A multimeter EXTECH model MV-110 to register currents and voltages in the system. Kaowool ceramic fiber insulation to cover internal and external surfaces of the reactor, see Fig. 5. Fuel composition was $96.86 \mathrm{wt} \%$ propane, $1.80 \mathrm{wt} \%$ Butane, $1.60 \mathrm{wt} \%$ ethane.

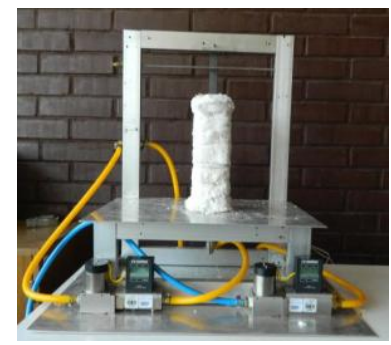

Fig. 5. Prototype burner assemby.

\section{RESUlts}

\section{A. Experimental Procedure}

The burner was fed initially with a stoichiometric air/fuel mixture at a total volumetric flow rate of $27 \mathrm{l} / \mathrm{min}$. Ignition of the gas mixture was through an external flame placed at the top of the reactor. With these operational conditions, upstream flame propagation was observed.

When the flame reached the interface of the porous bodies with different porosity, if there was no indication of interface flame stabilization, the fuel composition was decreased maintaining the total volumetric flow rate constant. This procedure was repeated for equivalence ratios 1.0, 0.9, 0.8, $0.7,0.6,0.5$ and 0.4 . Values of equivalence ratio below 0.5 did not produce stable combustion.

Once the operational variables for which the flame stabilizes at the interface were found, the TEM was installed on the reactor surface over quartz insulation. An external electrical resistance for matching condition and the multimeter were connected. Dimensions of the TEM are $40.0 \times 40.0 \times 3.4 \mathrm{~mm}$. 


\section{B. Experimental Results}

As the thermoelectric elements have a limit on the value of the maximum temperature, it is first searched a lean mixture (composition and velocity) that fulfills two main objectives: stopping the combustion front at the interface between the two porous media, such as those of Fig. 4, and developing the burner stationary temperature field with thermal levels below the limit on the thermoelectric elements.

With the outcomes of various tests, it was found that the flows of air and propane 26.4 and $0.561 /$ min respectively, giving $\Phi=0.5$, both objectives were achieved. Developed temperatures are presented in Fig. 6: the three thermocouples were installed so that they can touch the porous bodies through the iron shell (Fig. 4). The first thermocouple was installed at half the height of the first ceramic, the second at the interface between the different porous bodies and the third at half the height of the second ceramic.

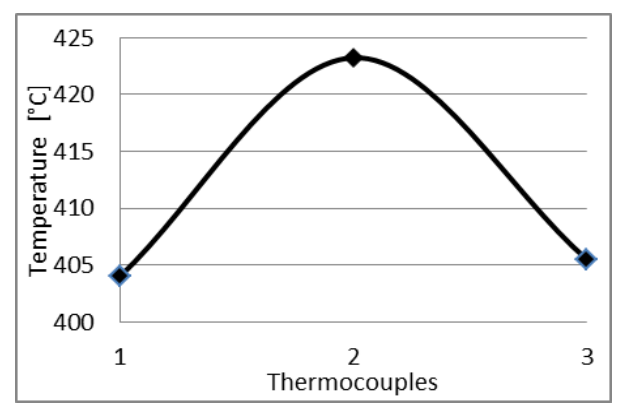

Fig. 6. Stationary temperatures along the burner for $\Phi=0.5$.

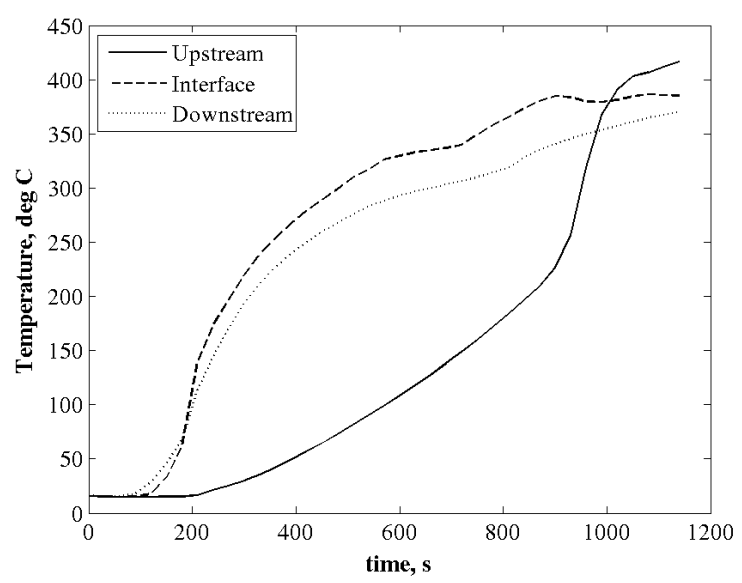

Fig. 7. Temperature evolution in thermocouples for equivalence ratio 1.0.

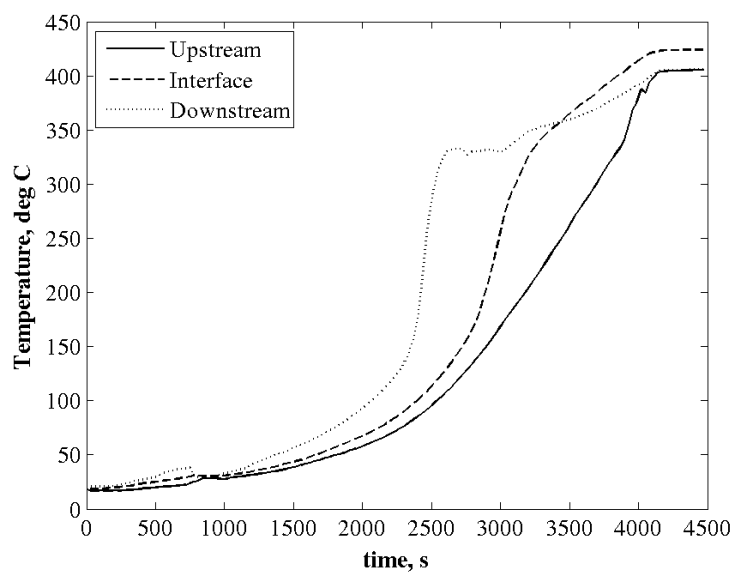

Fig. 8. Temperature evolution in thermocouples for equivalence ratio 0.5.

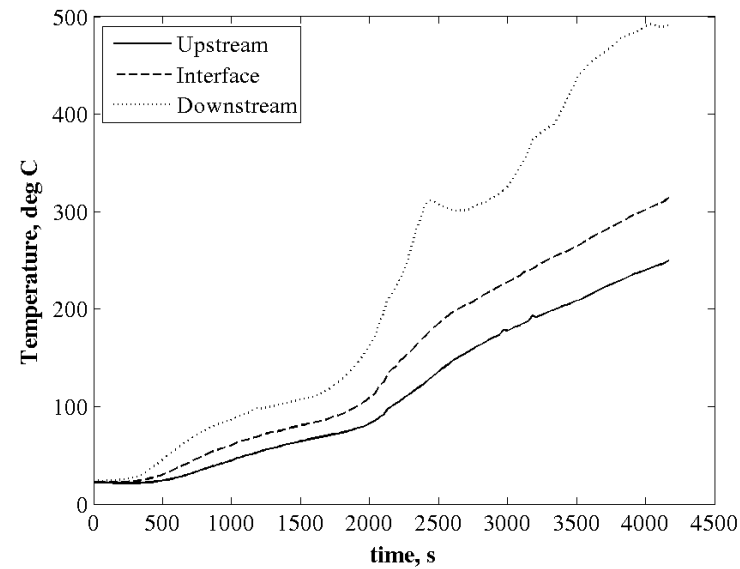

Fig. 9. Temperature evolution in thermocouples for equivalence ratio 0.4.

Figs. 7-9, show thermal profiles evolution registered with the C-type thermocouples in the flame stabilization phase of the study. It can be seen that only for the case of equivalence ratio of 0.5 (see Fig. 7) the flame is stopped at the interface since interface thermocouple register the higher thermal level at approximately $4000 \mathrm{~s}$ compared to the up and downstream thermocouples. In Fig. 7 at approximately 1090 s, it can be seen that the flame passes the interface and keeps propagating in the upstream direction. It is clear from Fig. 9 that the flame does not reach the interface for its stabilization to take place.

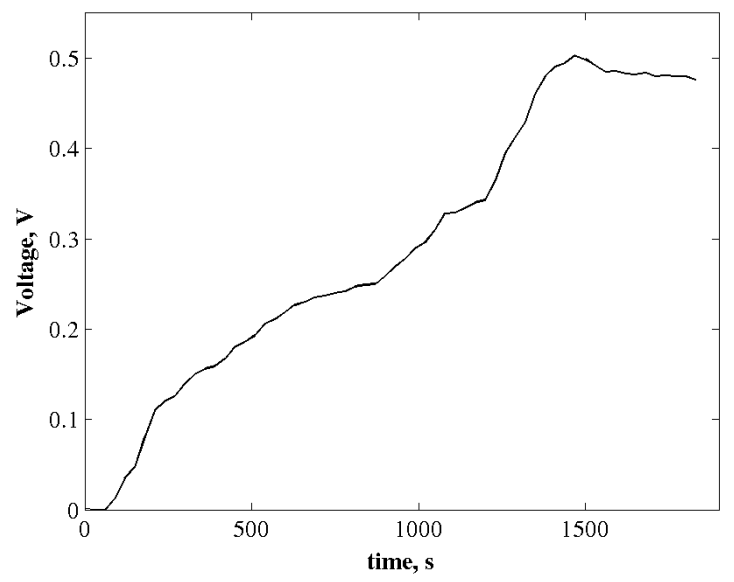

Fig. 10. Voltage evolution for equivalence ratio 0.5.

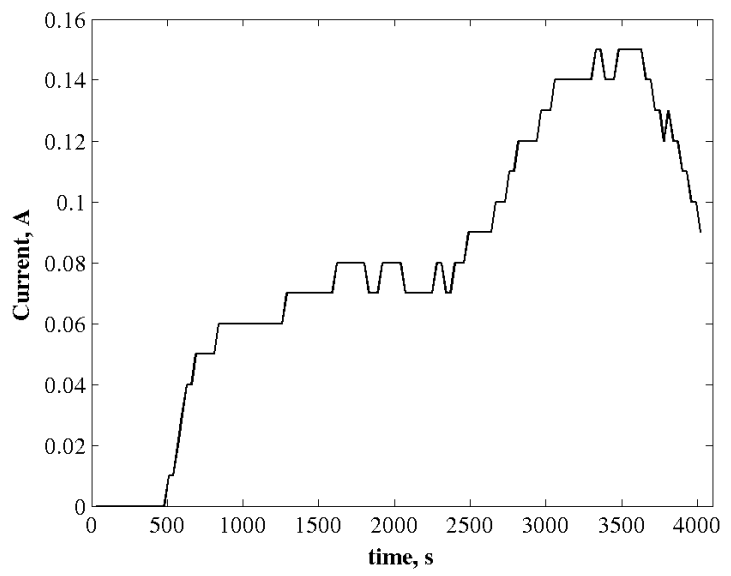

Fig. 11. Current evolution for equivalence ratio 0.5 .

Figs. 10-11, illustrate the evolution of voltage and electric 
current obtained. It can be seen that the voltage and current peaks were $0.503 \mathrm{~V}$ and $0.15 \mathrm{~A}$, respectively, so that the electric power of 0.075 watts was reached. If the reactor surface was entirelly covered the burner can theoretically give 1.5 watts of electrical power.

Clearly, the power achieved is not very high, but it represents the first attempt and marks the beginning of a series of works currently conducted at the University of Santiago de Chile to achieve better and more interesting results from the application standpoint.

\section{CONCLUSION}

Combustion flame stabilization was effectively achieved at the interface of two porous materials of different thermophysical properties for an equivalence ratio value of 0.5. Coupling of thermoelectric energy harvesting at the flame stabilization conditions, gives maximum values of voltage and current $503 \mathrm{mV}$ and $150 \mathrm{~mA}$ respectively.

\section{ACKNOWLEDGMENT}

This research was supported by Grants FONDECYT 1131156 and 11100401 awarded to V.B. and L.H. by the Chilean government, respectively.

\section{REFERENCES}

[1] A. J. Barra and J. L. Ellzey, "Heat recirculation and heat transfer in porous burners," Combustion and Flame, vol. 137, pp. 230-241, 2004.

[2] S. I. Foutko, I. S. Stanislav, S. A. Zhdanok, and L. A. Kennedy, "Superadiabatic combustion wave in a diluted methane-air mixture under filtration in a packed bed," in Proc. Symposium (International) on Combustion, vol. 26, 1994, pp. 3377-3382.

[3] S. A. Zhdanok, L. A. Kennedy, and G. Koester, "Superadiabatic combustion of methane air mixtures under filtration in a packed bed," Combustion and Flame, vol. 100, pp. 221-231, 1995.

[4] J. G. Hoffman, R. Echigo, H. Yoshida, and S. Tada, "Experimental study on combustion in a porous media with reciprocating flow system," Combustion and Flame, vol. 111, pp. 32-46, 1997.

[5] V.S. Babkin, I. Wierza, and G. A. Karim, "The phenomenon of energy concentration in combustion waves and its applications," Chemical Engineering Journal, vol. 91, pp. 279-285, 2003.

[6] J. R. Shi, M. Z. Xie, H. Liu, G. Li, and L. Zhou, "Numerical simulation and theoretical analysis of premixed low-velocity filtration combustion," International Journal of Innovations in Energy Systems and Power, vol. 51, pp. 1818-1829, 2008.

[7] V. I. Bubnovich, S. A. Zhdanok, and K. V. Dobrego, "Analytical study of the combustion waves propagation under filtration of methane-air mixture in a packed bed," International Journal of Heat and Mass Transfer, vol. 49, pp. 2578-2586, 2006.

[8] A. Knyazeva, V. Bubnovich, C. Rosas, and N. Moraga, "Theoretical analysis of premixed low-velocity filtration combustion for lewis number different from one," International Journal Heat and Mass Transfer, vol. 52, pp. 4938-4945, 2009.

[9] V. Bubnovich, L. Henríquez, and N. Gnesdilov, "Numerical study of the effects of the diameter of alumina balls on flame stabilization in a porous media burner," Numerical Heat Transfer: Part A, vol. 52, pp. 275-295, 2007.

[10] M. R. Henneke and J. L. Ellzey, "Modeling of filtration combustion in a packed bed", Combustion and Flame, vol. 117, pp. 832-840, 1999.
[11] L. A. Kennedy, J. P. Bingue, A. Saveliev, A. A. Fridman, and S. I. Foutko, "Chemical structures of methane-air filtration combustion waves for fuel-lean and fuel-rich conditions," Proceedings of the Combustion Institute, vol. 28, pp. 1431-1438, 2000.

[12] W. M. Mathis and J. L. Ellzey, "Flame stabilization, operating range and emissions for a methane/air porous burner," Combustion Science and Technology, vol. 175, pp. 825-839, 2003.

[13] V. Bubnovich, M. Toledo, L. Henríquez, C. Rosas, and J. Romero, "Flame stabilization between two beds of alumina balls in a porous burner," Applied Thermal Engineering, vol. 30, pp. 92-95, 2010.

[14] L. A. Kennedy, F. Contarin, A. V. Saveliev, and A. A. Fridman, "A reciprocal flow filtration combustor with embedded heat exchangers: numerical study," International Journal of Heat and Mass Transfer vol. 46, pp. 949-961, 2003.

[15] V. Bubnovich, L. Henríquez, C. Díaz, and M. Maiza, "Diameter of alumina balls effect on stabilization operation region for a reciprocal flow burner," International Journal of Heat and Mass Transfer, vol. 54, pp. 2026-2033, 2011.

[16] M. T Smucker and J. L Ellzey, "Computational and experimental study of a two-section porous burner," Combustion Science and Technology, vol. 176, pp. 1171-1189, 2004.

[17] G. Xiaolong and H. Xiao, and S. Yang, "Modeling, experimental study and optimization on low-temperature waste heat thermoelectric generator system," Applied Energy, vol. 87, pp. 3131-3136, 2010.

[18] I. Villela and J. L. Silveira, "Ecological efficiency in thermoelectric power plants," Applied Thermal Engineering, vol. 27, pp. 840-847, 2007.

[19] C. H. Cheng, S. Y. Huang, and T. C. Cheng, "A three-dimensional theoretical model for predicting transient thermal behavior of thermoelectric coolers," Heat and Mass Transfer, vol. 53, pp. 2001-2011, 2010.

[20] G. Min and D. M. Rowe, "Improved model for calculating the coeffcient of performance of a Peltier module," Energy Conversion and Management, vol. 41, pp. 163-171, 2000.

[21] C. W. Park and M. Kaviany, "Combustion-thermoelectric tube," Heat Transfer, vol. 122, pp. 721-729, 2000.

[22] J. A. Federici, D. G. Norton, T. Brüggemann, K. W. Voit, E. D. Wetzel, and D. G. Vlachos, "Catalytic micro-combustors with integrated thermoelectric elements for portable power production," Power Sources, vol. 161, pp. 1469-1478, 2006.

[23] K. Hanamura, T. Kumano, and Y. Iida, "Electric power generation by super-adiabatic combustion in thermoelectric porous element," Energy, vol. 30 , pp. 347-357, 2005 .

[24] V. I. Bubnovich, M. F. Maiza, and L. A. H. Vargas, "Analysis of thermal energy conversion into electric power inside a porous media burner," Theoretical Foundation of Chemical Engineering, vol. 46, no. 6, pp. 666-111, 2012.

[25] F. Katsuki, T. Tomida, H. Nakatami, M. Katoh, and A. Takata, "Development of a thermoelectric power generation system using reciprocating flow combustion in a porous FeSi2 element," Review of Scientific Instruments, vol. 72, pp. 3996-3999, 2001.

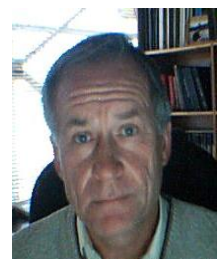

Valeri I. Bubnovich was born on March 151955 at Korelichi (Belarus). He got his M.S. from the Department of Physics, University of P. Lumumba, Moscow in 1981; Ph.D. from A. V. Luikov Heat Mass Transfer Institute, Belarus in 1990. He is now the Research Professor in the Department of Chemical Engineering, University of Santiago of Chile, Chile. His areas of research interest are heat mass transport in porous media, thermo fluids, computational simulation, finite differences, excess enthalpy flames and superadiabatic combustion, energy. Publications 38 in Journals ISI, 42 publications in International Conferences, collaboration in quality reviewer articles with the 19 international scientific journals, direction and participation in 10 projects of scientific research financed by the government of Chile (Fondecyt, Fondef, Corfo). 